\title{
El derecho a la jubilación patronal y el pago arbitrario de la pensión jubilar
}

The right to employer retirement and the arbitrary payment of the retirement pension

\author{
Claudio Terán-Vaca \\ ui.claudioteran@uniandes.edu.ec \\ Universidad Regional Autónoma de los Andes, Ibarra \\ Ecuador \\ http://orcid.org/0000-0002-8717-8391 \\ Melanie Limaico-Carcelén \\ di.melanieklc21@uniandes.edu.ec \\ Universidad Regional Autónoma de los Andes, Ibarra \\ Ecuador \\ http://orcid.org/0000-0001-9905-9659 \\ Estefanía Toapanta-Cacuango \\ di.estefaniamtc95@uniandes.edu.ec \\ Universidad Regional Autónoma de los Andes, Ibarra \\ Ecuador \\ https://orcid.org/0000-0003-4520-1853
}

Recepción: 15 de septiembre 2021

Revisado: 25 octubre 2021

Aprobación: 15 de noviembre 2021

Publicación: 01 de diciembre 2021 


\section{Estimado Editor (a):}

La Carta Magna del año 2008, en su capítulo segundo trata del Buen Vivir, sin embargo, en las actuales circunstancias, las condiciones de vida de los jubilados son dificultosas por no recibir una jubilación patronal digna, tomando en cuenta que las jubilaciones que perciben por parte del IESS no son lo suficientemente altas. En definitiva, parece que los jubilados viven una injusticia frente a las pensiones que perciben. De igual manera, la misma norma suprema en su Artículo 33 garantiza a las personas trabajadoras el pleno respeto a su dignidad, una vida decorosa, remuneraciones y retribuciones justas.

En este sentido, el Código de Trabajo (2005) lo define:

Artículo 216. Es la pensión vitalicia que tiene derecho a recibir de su empleador, los trabajadores que por veinte y cinco o más años hubieren prestado sus servicios de manera continua o interrumpidamente.

La jubilación es un proceso que todo trabajador anhela llegar tras una larga vida laboral, muchas veces esta es complicada por diversas situaciones como el despido anticipado a pocos meses o años de completarla. Actualmente en el Ecuador se busca transformar la jubilación laboral y que esta sea cambiada por un aporte que cubra el empleador a un fondo que destine el trabajador para que al final de 25 años retire el monto con los intereses ganados sin importar que haya cambiado de empresa.

En cambio, en la jubilación por vejez por el IESS, el afiliado debe estar cesante, cumplir más de 60 años y tener las imposiciones necesarias que van desde 120 a más de 480 (10 a 40 años de aportación) de acuerdo a la edad. Además, el Artículo 188 también contempla la jubilación patronal proporcional para aquellos que cumplieron más de 20 años y menos de 25 años de servicio en el caso de despido intempestivo. La patronal se puede entregar de manera mensual o global.

Por otro lado, en el Ecuador existe la doble jubilación, es decir, coexisten dos clases de jubilación: la jubilación patronal y la jubilación general del Instituto Ecuatoriano de Seguridad Social- IESS. La primera, según el Código del Trabajo (2005), artículo 216, es una renta vitalicia -más un año posterior a la muerte del jubilado- y se da cuando "los trabajadores que por veinticinco años o más hubieren prestado servicios, 
continuada o interrumpidamente, tendrán derecho a ser jubilados por sus empleadores (...)" Y la jubilación del IESS, según el artículo 185 de la Ley de Seguridad Social, es una renta, también vitalicia, que se le otorga al afiliado cuando haya cumplido sesenta (60) años de edad y un mínimo de trescientos sesenta (360) imposiciones mensuales o un mínimo de cuatrocientos ochenta (480) imposiciones mensuales sin límite de edad.

La pensión jubilar es un derecho del trabajador por lo que es irrenunciable y de total exigibilidad, lo que garantiza que el trabajador cobre su jubilación patronal o en el peor de los casos demande de ella. Tal como indica la Constitución de la República del Ecuador de 2008, en su Artículo 45 que todos los ecuatorianos están protegidos por la garantía de derechos que hace sujetos de protección a todos quienes conforman la población del territorio ecuatoriano, partiendo de este conocimiento se debe contemplar que todos los ecuatorianos sin excepción están protegidos por la Constitución, también existen grupos en los que los derechos son mucho más contemplativos y considerativos, es el caso de los grupos de atención prioritarios en donde se encuentran, los niños, niñas y adolescentes, mujeres, discapacitados, adultos mayores, personas privadas de la libertad, entre otros. Sin embargo, a la mayor parte de extrabajadores, sus empleadores les pagan la pensión jubilar, pero de forma arbitraria ya que no se usa un instrumento válido que contemple bases para el cálculo de ley. Tomando en cuenta los aspectos legales y doctrinarios y aún más las opiniones públicas acerca del tema, pudiendo evidenciar que las jubilaciones patronales que se están pagando a los trabajadores en el país transgreden el Artículo 216, inciso 2 del Código de Trabajo que establece la cantidad y la proporcionalidad del monto a cobrar, cosas que no sucede en varios sectores laborales del Ecuador. El tiempo que debe transcurrir para acceder a la jubilación patronal es de 25 años continuados o interrumpidos en los que el exempleado haya prestado sus servicios al mismo empleador. No obstante, se puede acceder también a la parte proporcional de la jubilación patronal si el empleado fue despedido intempestivamente entre los 20 y 25 años. El objeto de esta jubilación o plan de empresa es complementar la pensión pública del jubilado. El trabajador debe saber de la indispensable y hasta imperiosa 
necesidad de tener este derecho, entre otras cosas porque el primer pilar (la parte de reparto) que puede ser exigua, no debe ser la única fuente de ingresos para su sostenimiento durante el resto de su vida. Es necesario insistir que los expertos alertan desde hace años que la tasa de sustitución (relación pensión vs. último ingreso como activo) va a bajar inexorablemente. El Estado no puede garantizar una pensión con una tasa de sustitución superior al 60\%, razón por la que existe la Seguridad Social Complementaria.

En tal sentido, el Artículo 208 de la Ley para la Promoción de la Inversión y de la Participación Ciudadana, dispone que el empleador que no haya pagado la pensión a su jubilado y éste haya tenido que demandarle, pagará el interés que estuviere vigente para préstamo a un corto plazo al momento de dictarse la sentencia definitiva, calculada desde la fecha en que según lo dispuesto en la sentencia e inclusive hasta el momento en que ésta se ejecute y se pague los valores correspondientes.

Para finalizar, según el Código del Trabajo vigente, todo trabajador que ha laborado 25 años o más con el mismo empleador tiene derecho a recibir por parte de la empresa una pensión en forma vitalicia y al fallecimiento del jubilado, una anualidad para sus derechohabientes. Es importante la valoración de una provisión que garantice el pago esperado de las pensiones mensuales. A pesar de la normativa existente en el Ecuador, en cuanto al derecho a la jubilación patronal, existen varios empleadores que piensan primero en ellos, en aprovecharse económicamente de los demás al no proporcionarles lo que les corresponde a los extrabajadores por jubilación patronal. Realizan un pago ilegal, indebido y arbitrario, perjudicando al extrabajador sin importarles en qué situación se encuentre. La discriminación se genera en los prejuicios o características negativas que se le asignan a un grupo o sector, pero que generalmente son injustas o equivocadas. (Villegas, 2014, p. 39)

Por esto, se debe conocer la forma correcta de reclamar y ejercer el derecho a la jubilación patronal para que este se realice respetando el debido proceso y siguiendo los principios fundamentales del mismo, para que el pago de esta pensión jubilar sea justo y equitativo. 


\section{FINANCIAMIENTO}

No monetario.

\section{AGRADECIMIENTO}

A la Universidad Regional Autónoma de los Andes, Ibarra, por motivar el desarrollo de la Investigación.

\section{REFERENCIAS CONSULTADAS}

Asamblea Nacional Constituyente de la República del Ecuador, (2008). Constitución de la República del Ecuador. [Constitution of the Republic of Ecuador]. Montecristi. Registro Oficial 449 de 20-oct-2008. Recuperado de https://n9.cl/sia

Asamblea Nacional de la República del Ecuador (2005). Código del Trabajo de la República del Ecuador. [Labour Code of the Republic of Ecuador] Quito, Ecuador. Registro Oficial de la República del Ecuador Número 167. 16 de diciembre de 2005. Última reforma 20 de abril de 2015. Recuperado de: https://n9.cl/652cf

Constitución Política de la República (2000) Ley para la promoción de la inversión y participación ciudadana. [Law for the promotion of investment and citizen participation]. Ley No. 000. RO/ Sup 144 de 18 de agosto del 2000.Recuperado de: https://n9.cl/8mb0k

Villegas Romero, N. (2014). La licencia por matrimonio, el código del trabajo y el principio de igualdad ante la ley.[Marriage leave, the labour code and the principle of equality before the law]. Tesis de grado. Universidad Regional Autonoma de los Andes. Recuperado de: https://n9.cl/wuz49 